\title{
RESULTS FROM THE 2007 WORLD RADIOCOMMUNICATION CONFERENCE (WRC-07) FOR REMOTE SENSING AND A PREVIEW OF ISSUES FOR THE 2011 WRC
}

\author{
John E. Zuzek \\ NASA \\ john.e.zuzek@nasa.gov
}

\begin{abstract}
The 2007 World Radiocommunication Conference considered and adopted a number of changes to the international Radio Regulations that have a direct bearing on remote sensing interests throughout the world. Changes to the Radio Regulations were made to better define the interference protection afforded to passive sensors in the 1400-1427 MHz, 10.6-10.68 GHz, 23.6-24 GHz, 31.3-31.5 $\mathrm{GHz}, 36-37 \mathrm{GHz}, 50.2-50.4 \mathrm{GHz}$, and $52.6-54.25 \mathrm{GHz}$ passive bands for WRC-07 Agenda Items 1.2, 1.17 and 1.20. An extension to the active sensing allocation around 9.5-9.8 GHz under Agenda Item 1.3 was also adopted. The results of WRC-07 as they pertain to remote sensing and a preview of the remote sensing issues at WRC-11 are discussed.
\end{abstract}

Index Terms - remote sensing; radiospectrum management; electromagnetic radiative interference

\section{INTRODUCTION}

The World Radiocommunication Conference (WRC) is the body that decides on changes to the International Telecommunications Union (ITU) Radio Regulations, the treaty rules which govern the global use of radio frequency spectrum throughout the world. The ITU is itself a United Nations (UN) body. A World Radiocommunication Conference occurs approximately every 4 years to review various aspects of these Radio Regulations. Any UN member nation, known as "administrations", can participate in a WRC and each has equal standing. The 2007 World Radiocommunication Conference (WRC-07) was held in Geneva Switzerland from 22 October through 16 November 2007 and approximately 2800 attendees from 164 Member States (i.e., countries) participated in WRC-07 with 155 countries signing the Final Acts which comprise the treaty text that modified the international Radio Regulations. The four week long Conference considered large numbers of proposals on the various agenda items which were set forth by the previous WRC in 2003 as the agenda for the next Conference. This WRC decided on the agenda for the next
WRC which is tentatively scheduled for November of 2011. The exact date and venue of the next Conference will be decided in November of this year when the ITU Council meets. The discussion in this document is based on the results of the WRC-07 where the author was a US Delegate to the Conference and was materially involved in several agenda items of interest and concern to the remote sensing community.

\section{RESULTS OF WRC-07}

The 2007 Conference agenda contained a number of items that have a direct bearing on remote sensing interests throughout the world as well as several items that have a less direct or obvious impact on remote sensing. Remote sensing scientists need to be aware of frequency allocations and the regulatory protection, or lack thereof, for any frequency band allocated to the Earth exploration-satellite service (EESS) for the purpose of either active or passive remote sensing of the Earth and its atmosphere.

In particular, the agenda items that have the most direct effect on remote sensing applications and their frequency allocations were Agenda Items 1.2, 1.3, 1.17 and 1.20. Agenda Item 1.2 dealt with two separate issues, the consideration of sharing between the fixed and mobile terrestrial services and the EESS (passive) in the bands $10.6-10.68 \mathrm{GHz}$ and $36-37 \mathrm{GHz}$ being of interest to the remote sensing community. Agenda Item 1.3 also dealt with two separate issues, only one of which is of interest to the remote sensing community, which was a possible extension of $200 \mathrm{MHz}$ to the existing allocation to the EESS (active) in the 9.5-9.8 GHz band. The goal of this extension was to have a contiguous $500 \mathrm{MHz}$ band available for such things as synthetic aperture radar (SAR) mapping of the Earth's surface topology. Agenda Item 1.17 dealt with an existing allocation made by the preceding Conference, WRC-03, in two bands around the $1400-1427 \mathrm{MHz}$ passive band for use by mobile-satellite service (MSS) feederlink earth stations transmitting to/from low Earth orbiting mobile satellite systems. The concern here was mainly the out-ofband emissions from uplink transmissions of these earth stations spilling over into the passive band and corrupting measurements taken in that band. Agenda Item 1.20 is similar to Agenda Item 1.17 in type, but with a much 
broader scope. This agenda item dealt with the protection of passive sensors on board Earth observing remote sensing satellites from out-of-band emissions of various active communications services that operate in bands either adjacent to or nearby several passive remote sensing bands in which emissions are prohibited (i.e., the passive bands in question were the $1400-1427 \mathrm{MHz}$ band, the $23.6-24.0 \mathrm{GHz}$ band, the $31.3-31.5 \mathrm{GHz}$ band and the 50.2-50.4 GHz band). For each of these agenda items, the technical studies performed within the ITU Radiocommunications Sector (ITU-R) were presented and discussed in [1]. The results of the WRC-07 itself are given in [2] as they will appear in the next version of the international Radio Regulations. It should be noted that World Radiocommunication Conferences are treaty negotiations for the international Radio Regulations. While such negotiations consider the results of the technical studies done by the ITU-R Study Groups, the results of World Radiocommunication Conferences are much more heavily influenced by political factors and are, in essence, negotiated political solutions to technical problems.

\subsection{Passive Sensing in $10.6-10.68$ and $36-37 \mathrm{GHz}$}

WRC-07 Agenda Item 1.2 considered the in-band sharing situation between passive sensors operating in the Earth exploration-satellite service, or EESS (passive), and terrestrial microwave transmitters operating in the fixed and mobile services in the $10.6-10.68 \mathrm{GHz}$ and $36-37 \mathrm{GHz}$ frequency bands. Proposals on this agenda item were fairly split between a desire for mandatory emission limits and recommended emission limits in the 10.6-10.68 GHz band since many countries already have large deployments of fixed or mobile systems in this band. In these bands, the EESS (passive), fixed and mobile services have equal regulatory status. That is, the frequency bands in question are allocated to these services on a co-primary basis meaning all of the services have equal rights in using these frequency bands and must not cause harmful interference to the other co-primary services. It should be noted that "harmful interference" is a regulatory term defined as "Interference which endangers the functioning of a radionavigation service or of other safety services or seriously degrades, obstructs, or repeatedly interrupts a radiocommunication service operating in accordance with Radio Regulations." Therefore, if a service causes radio frequency interference to another service, it is not necessarily considered "harmful interference".

Because the 10.6-10.68 GHz band is heavily used by the fixed service throughout many parts of the world, there was rather strong opposition by some administrations to imposing more stringent limits on the FS than already existed in this band in order to protect the spaceborne passive sensors. Conversely, the vast majority of proposals for the $36-37 \mathrm{GHz}$ band were for mandatory emission limits on the fixed and mobile to protect the long term interests of passive sensing in this band. This band is somewhat different than the 10.6-10.68 GHz band in two significant ways. First, the $36-37 \mathrm{GHz}$ band is not heavily used by the terrestrial services at this time and second, this band did not have any existing emission limits on the terrestrial service operations. Therefore, there was general agreement in many of the proposals that some limitations on the transmissions of the terrestrial services were needed now to protect the use of the $36-37 \mathrm{GHz}$ band into the future.

During the second week of WRC-07, it became obvious that mandatory emission limits on the fixed and mobile services in the $36-37 \mathrm{GHz}$ band had an overwhelming amount of support. Somewhat surprisingly, there also was a growing momentum towards adopting mandatory emission limits in the 10.6-10.68 GHz band, although such limits would have to be gradually phased in over many years and existing terrestrial microwave systems would have to be exempted from such limits. At the same time, little or no progress had been made on Agenda Item 1.20 dealing with protection of passive sensors from unwanted out-of-band emissions into certain passive frequency bands. This situation was problematic for the Conference because many countries viewed these two agenda items as being linked together since both dealt with protection of passive remote sensing, albeit in quite different situations. As a result of this perceived linkage, during the third week of the Conference, a compromise was negotiated which included Agenda Item 1.20 as well as Agenda Item 1.2.

Table 1: Recommended Limits for 10.6-10.68 GHz Band

\begin{tabular}{|c|c|c|}
\hline \multicolumn{3}{|c|}{ Fixed Stations of point-to-point systems } \\
\hline Parameter & Desired & Actual \\
\hline Maximum elevation angle & $20^{\circ}$ & $20^{\circ}$ \\
\hline $\begin{array}{l}\text { Maximum transmitter power at } \\
\text { antenna }\end{array}$ & $-15 \mathrm{dBW}$ & $-15 \mathrm{dBW}$ \\
\hline \multicolumn{3}{|c|}{ Fixed Hub Stations of point-multipoint systems } \\
\hline $\begin{array}{l}\text { Maximum transmitter power at } \\
\text { antenna }\end{array}$ & $-17 \mathrm{dBW}$ & $-7 \mathrm{dBW}$ \\
\hline Maximum e.i.r.p. & $-4 \mathrm{dBW}$ & N/A \\
\hline Maximum off-axis e.i.r.p. above $20^{\circ}$ & N/A & $-6 \mathrm{dBW}$ \\
\hline Maximum off-axis e.i.r.p. above $45^{\circ}$ & N/A & $-11 \mathrm{dBW}$ \\
\hline Maximum off-axis e.i.r.p. at $90^{\circ}$ & $\mathrm{N} / \mathrm{A}$ & $-13 \mathrm{dBW}$ \\
\hline \multicolumn{3}{|c|}{ Fixed Customer Stations of point-to-multipoint systems } \\
\hline Maximum elevation angle & $20^{\circ}$ & $20^{\circ}$ \\
\hline $\begin{array}{l}\text { Maximum transmitter power at } \\
\text { antenna }\end{array}$ & $-10 \mathrm{dBW}$ & $-8 \mathrm{dBW}$ \\
\hline Maximum off-axis e.i.r.p. above $45^{\circ}$ & N/A & $-18 \mathrm{dBW}$ \\
\hline \multicolumn{3}{|c|}{ Mobile Service Stations } \\
\hline $\begin{array}{l}\text { Maximum transmitter power at } \\
\text { antenna }\end{array}$ & $-17 \mathrm{dBW}$ & $-17 \mathrm{dBW}$ \\
\hline
\end{tabular}


The result was that non-mandatory/recommended limits were established in the lower frequency bands where significant active service deployments currently exist in exchange for mandatory limits being adopted in the higher frequency bands where little or no current active service deployment exists today. Thus, the Conference agreed to recommended limits in addition to the existing mandatory emission limits for the $10.6-10.68 \mathrm{GHz}$ band and mandatory emission limits in the $36-37 \mathrm{GHz}$ band given in Tables 1 and 2 , respectively.

Table 2: Mandatory Limits for 36-37 GHz Band

\begin{tabular}{|l|l|l|}
\hline \multicolumn{3}{|c|}{ Fixed Stations of point-to-point systems } \\
\hline \multicolumn{1}{|c|}{ Parameter } & \multicolumn{1}{c|}{ Desired } & Actual \\
\hline Maximum elevation angle & $20^{\circ}$ & $20^{\circ}$ \\
\hline $\begin{array}{l}\text { Maximum transmitter power at } \\
\text { antenna }\end{array}$ & $-10 \mathrm{dBW}$ & $-10 \mathrm{dBW}$ \\
\hline
\end{tabular}

\begin{tabular}{|c|c|c|}
\hline \multicolumn{3}{|c|}{ Fixed Hub Stations of point-multipoint systems } \\
\hline Maximum elevation angle & $20^{\circ}$ & $20^{\circ}$ \\
\hline $\begin{array}{l}\text { Maximum transmitter power at } \\
\text { antenna }\end{array}$ & $-10 \mathrm{dBW}$ & $-5 \mathrm{dBW}$ \\
\hline Maximum e.i.r.p. & $-12 \mathrm{dBW}$ & N/A \\
\hline \multicolumn{3}{|c|}{ Fixed Customer Stations of point-to-multipoint systems } \\
\hline Maximum elevation angle & $20^{\circ}$ & $20^{\circ}$ \\
\hline $\begin{array}{llll}\begin{array}{l}\text { Maximum } \\
\text { antenna }\end{array} & \text { transmitter power at } \\
\end{array}$ & $-10 \mathrm{dBW}$ & $-10 \mathrm{dBW}$ \\
\hline \multicolumn{3}{|c|}{ Mobile Service Stations } \\
\hline $\begin{array}{l}\text { Maximum transmitter power at } \\
\text { antenna }\end{array}$ & $-10 \mathrm{dBW}$ & $-10 \mathrm{dBW}$ \\
\hline
\end{tabular}

\subsection{Extension for Active Sensing around $9500 \mathrm{MHz}$}

Agenda Item 1.3 dealt with an extension of up to $200 \mathrm{MHz}$ to the existing allocation to the EESS (active) in the 9500$9800 \mathrm{MHz}$ band. Such and extension would result in a contiguous $500 \mathrm{MHz}$ band for active remote sensing with improved resolution for such things as synthetic aperture radar (SAR) mapping of the Earth's surface topology.

Proposals to the Conference for this agenda item overwhelmingly favored extending the EESS (active) allocation into the $9300-9500 \mathrm{MHz}$ band. However, one regional group of administrations proposed an additional extension into the $9800-9900 \mathrm{MHz}$ band to provide a contiguous $600 \mathrm{MHz}$ of bandwidth for these active spaceborne sensors. Such an additional increase in bandwidth would enable improvements in performance for imaging and in resolution for topographical interferometric applications from spaceborne SARs. This additional 100 $\mathrm{MHz}$ proposal caused quite a bit of consternation at the Conference. While studies within the ITU-R Study Groups had shown that the active spaceborne sensors could share either the upper or lower extension bands with the incumbent services, there was a procedural problem for many administrations because of the way the agenda item was written back at WRC-03. Because the agenda item stated that the possible extension to the EESS (active) was for "up to $200 \mathrm{MHz}$ ", an additional $100 \mathrm{MHz}$ extension was viewed as being outside the scope of the agenda item. These types of procedural exceptions are rarely made at World Radiocommunication Conferences, no matter how compelling the technical evidence is to support such an action nor how pragmatic the action might be.

The baseline $200 \mathrm{MHz}$ extension to the primary allocation to EESS (active) into the band 9300-9500 $\mathrm{MHz}$ was adopted towards the middle of the Conference without too much difficulty. However, the problem of the additional $100 \mathrm{MHz}$ allocation to the EESS (active) was not resolved until the final days of the Conference. It was finally decided that the extension to the EESS (active) allocation would be made on a secondary basis into the 9800-9900 $\mathrm{MHz}$ band with numerous constraints on the allocation to ensure the protection of the incumbent radiocommunication services.

The resultant allocation to the EESS (active) provides a contiguous $500 \mathrm{MHz}$ primary allocation (or $600 \mathrm{MHz}$ if the secondary allocation is also used) for very high resolution topographical mapping and interferometry from space.

\subsection{Protection of Passive Sensing in the 1400-1427 MHz Band from MSS Feederlinks}

Agenda Item 1.17 dealt with an existing allocation made by the 2003 World Radiocommunication Conference (WRC03 ) in two bands around the important $1400-1427 \mathrm{MHz}$ passive band for use by mobile-satellite service (MSS) feederlink earth stations transmitting to/from low Earth orbiting mobile satellite systems. The concern for passive remote sensing operations was mainly with the out-of-band emissions from uplink transmissions of these earth stations spilling over into the passive sensing band and corrupting measurements taken in that band.

The result of the WRC-07 was that these troublesome feederlink allocations were "suppressed" from the Table of Allocations in the Radio Regulations. This means that the allocations and their associated footnote were deleted and no longer exists, thus avoiding the possible interference problem in the future.

\subsection{Protection of Sensors from Out-of-Band Emissions}

Agenda Item 1.20 dealt with the protection of passive remote sensing instruments operating on board Earth observing remote sensing satellites from out-of-band emissions of various active communications services that operate in bands either adjacent to or nearby several purely passive remote sensing bands in which all emissions are prohibited. 
This was one of the most contentious issues that the Conference addressed because the active service proponents (i.e., predominantly the commercial telecommunications operators) did not want the additional burden or possible expense of a requirement to filter their out-of-band emissions to the extent necessary to protect the spaceborne passive sensors. This lead many administrations to adopt the position that any out-of-band emission limits to one service to protect another service in an adjacent frequency band might set a bad precedent and create a tidal wave of out-of-band emission issues at future Conferences. Furthermore, the necessity of such out-of-band limits for bands where current systems do not appear to cause such interference was questioned by such administrations. Other administrations took a more moderate view that out-of-band emission limits in the higher frequency bands where little or no use was present would prevent such out-of-band interference problems in the future to many important remote sensing frequency bands.

As mentioned in the previous discussion on Agenda Item 1.2, there was a "grand compromise" brokered towards the end of the Conference between AI 1.2 and 1.20 that allowed recommended unwanted emission limits to be adopted for lower frequency bands (i.e., in this case, the active services around the 1400-1427 MHz passive sensing band) while mandatory unwanted emission limits were adopted for active services in adjacent bands above $20 \mathrm{GHz}$. In this case, that means that the inter-satellite service in the band $22.55-23.55 \mathrm{GHz}$, the fixed service in the bands $31-$ 31.3 GHz and 51.4-52.6 GHz, and the fixed-satellite service uplinks in the bands 49.7-50.2 GHz and 50.4-50.9 GHz all have to comply with mandatory unwanted emission limits to help protect the passive sensors operating in the 23.6-24 $\mathrm{GHz}, 31.3-31.5 \mathrm{GHz}, 50.2-50.4 \mathrm{GHz}$ and $52.6-54.25 \mathrm{GHz}$ bands. There is one exception to these results and that is the band $30-31 \mathrm{GHz}$ which is allocated to the fixed-satellite service for uplinks to communications satellites. This frequency band is not adjacent to a passive band and because of this, there was not really a great need to implement mandatory limits since the nearest passive band is $300 \mathrm{MHz}$ away. So WRC-07 adopted only recommended limits for the $30-31 \mathrm{GHz}$ fixed-satellite service uplink outof-band emissions.

The recommended out-of-band emission limits emissions limits are given in Table 3 and the mandatory outof-band emission limits are given in Table 4.

\section{REMOTE SENSING ISSUES FOR WRC-11}

WRC-07 set the agenda for WRC-11 to take place tentatively in November of 2011. There is one agenda item with a direct impact on remote sensing interests and that is AI 1.6 which deals with reviewing footnote 5.565 of the Radio Regulations in order to update the frequency bands needed for passive remote sensing between $275-3000 \mathrm{GHz}$.
Expertise from IEEE GRSS would be welcomed to help define these needs.

Table 3: Recommended Limits for Active Services

\begin{tabular}{|c|c|c|}
\hline \multicolumn{3}{|c|}{ Emissions into 1400 - $1427 \mathrm{MHz}$ Passive Band } \\
\hline $\begin{array}{l}\text { Active } \\
\text { Band }\end{array}$ & Active Service & $\begin{array}{c}\text { Maximum Unwanted } \\
\text { Emission Level in Passive } \\
\text { Band }\end{array}$ \\
\hline \multirow{3}{*}{$\begin{array}{l}1350-1400 \\
\mathrm{MHz}\end{array}$} & Radiolocation & $-29 \mathrm{dBW}$ \\
\hline & Fixed & $-45 \mathrm{dBW}$ for P-P Systems \\
\hline & Mobile & $\begin{array}{l}-60 \mathrm{dBW} \text { for regular mobile } \\
-45 \mathrm{dBW} \text { for transportable }\end{array}$ \\
\hline \multirow{3}{*}{$\begin{array}{c}1427-1429 \\
\mathrm{MHz}\end{array}$} & Space Ops (E-s) & $-36 \mathrm{dBW}$ \\
\hline & Mobile & $\begin{array}{l}-60 \mathrm{dBW} \text { for regular mobile } \\
-45 \mathrm{dBW} \text { for transportable }\end{array}$ \\
\hline & Fixed & $-45 \mathrm{dBW}$ for P-P Systems \\
\hline \multirow[t]{2}{*}{$\begin{array}{l}1429-1452 \\
\mathrm{MHz}\end{array}$} & Mobile & $\begin{array}{l}-60 \mathrm{dBW} \text { for regular mobile } \\
-45 \mathrm{dBW} \text { for transportable } \\
-28 \mathrm{dBW} \text { for aeronautical }\end{array}$ \\
\hline & Fixed & $-45 \mathrm{dBW}$ for P-P Systems \\
\hline \multicolumn{3}{|c|}{ Emissions into the 31.3-31.5 GHz Passive Band } \\
\hline $\begin{array}{l}30.0-31.0 \\
\mathrm{GHz}\end{array}$ & $\begin{array}{l}\text { Fixed-Satellite } \\
\text { (Earth-to-space) }\end{array}$ & $\begin{array}{l}-9 \mathrm{dBW} \text { for antenna } \geq 56 \mathrm{dBi} \\
-20 \mathrm{dBW} \text { for antenna }<56 \mathrm{~dB}\end{array}$ \\
\hline
\end{tabular}

Table 4: Mandatory Limits for Various Active Services

\begin{tabular}{|c|c|c|}
\hline \multicolumn{3}{|c|}{ Emissions into 23.6-24.0 GHz Passive Band } \\
\hline $\begin{array}{l}\text { Active } \\
\text { Band }\end{array}$ & Active Service & $\begin{array}{c}\text { Maximum Unwanted } \\
\text { Emission Level in Passive } \\
\text { Band }\end{array}$ \\
\hline $\begin{array}{l}22.55- \\
23.55 \mathrm{MHz}\end{array}$ & Inter-Satellite & $\begin{array}{l}-36 \mathrm{dBW} \text { in any } 200 \mathrm{MHz} \\
\text { prior to } 2020 \text { and } \\
-46 \text { in any } 200 \mathrm{MHz} \\
\text { after } 1 \text { January } 2020\end{array}$ \\
\hline \multicolumn{3}{|c|}{ Emissions into the 31.3-31.5 GHz Passive Band } \\
\hline $\begin{array}{c}\text { 31.0-31.3 } \\
\mathrm{GHz}\end{array}$ & $\begin{array}{l}\text { Fixed } \\
\text { (excluding } \\
\text { HAPS) }\end{array}$ & $\begin{array}{l}-38 \mathrm{dBW} \text { in any } 100 \mathrm{MHz} \text { after } \\
1 \text { January } 2012\end{array}$ \\
\hline \multicolumn{3}{|c|}{ Emissions into the 50.2-50.4 GHz Passive Band } \\
\hline $\begin{array}{c}49.7-50.2 \\
\text { GHz }\end{array}$ & \multirow{2}{*}{$\begin{array}{l}\text { Fixed-Satellite } \\
\text { (Earth-to-space) }\end{array}$} & \multirow{2}{*}{$\begin{array}{l}-10 \mathrm{dBW} \text { for antenna } \geq 57 \mathrm{dBi} \\
-20 \mathrm{dBW} \text { for antenna }<57 \mathrm{dBi}\end{array}$} \\
\hline $\begin{array}{c}504 .-50.9 \\
\mathrm{GHz}\end{array}$ & & \\
\hline \multicolumn{3}{|c|}{ Emissions into the 52.6-54.25 GHz Passive Band } \\
\hline $\begin{array}{c}51.4-52.6 \\
\mathrm{GHz}\end{array}$ & Fixed & $-33 \mathrm{dBW}$ in any $100 \mathrm{MHz}$ \\
\hline
\end{tabular}

\section{REFERENCES}

[1] Zuzek, J.E., "Spectrum Allocation Issues Affecting Remote Sensing for the 2007 World Radiocommunication Conference (WRC-07)," IGARSS 2007, IEEE International, pp $2702-2705,23-28$ July 2007.

[2] "Final Acts of the 2007 World Radiocommunication Conference", International Telecommunications Union, Geneva, Switzerland, 22 October - 16 November 2007. 